\title{
Prevalence and Treatment Outcome of Nasolacrimal Duct Obstruction in Saudi Children with Down Syndrome
}

Lujain Abdu ${ }^{1}$, Noor Bawahab ${ }^{2}$, Raghad W. Mohammed Hussain ${ }^{3}$, Hesham Qary ${ }^{1}$, Asalh Saeedi ${ }^{1}$, Nizar Alhibshi ${ }^{4}$

1. Medicine, King Abdulaziz University, Jeddah, SAU 2. Pediatric, King Abdulaziz University Hospital, Jeddah, SAU 3. Pediatrics, King Abdulaziz University Hospital, Jeddah, SAU 4. Ophthalmology, King Abdulaziz University Hospital, Jeddah, SAU

Corresponding author: Lujain Abdu, lujain.a.abdu@gmail.com

\section{Abstract \\ Introduction}

Congenital nasolacrimal duct obstruction (CNLDO) is one of the most common congenital abnormalities encountered by pediatric ophthalmologists, occurring in $20-30 \%$ of all neonates (range: 6-84\%). The majority of the cases (up to 90\%) resolve within the first year of birth. Many syndromes, such as Down syndrome, are associated with congenital lacrimal anomalies. The prevalence of nasolacrimal anomalies in Down syndrome has been reported to be $22 \%$.

\section{Methods}

This was a retrospective study of all children diagnosed with Down syndrome at King Abdulaziz University Hospital (KAUH), Jeddah, Saudi Arabia between 2010 and 2015.

\section{Result}

The total sample size was 175 patients; 15 patients were diagnosed with CNLDO with a prevalence of $8.57 \%$. The prevalence among the gender was $53.3 \%$ male and $46.7 \%$ female, with a median age of eight years. Regarding ocular disorders, $20.0 \%$ cases were diagnosed with refractive error, $13.3 \%$ with nystagmus, and $13.3 \%$ with blepharitis. Myopia, strabismus, conjunctivitis, and cataract were observed in four different patients, and the remaining four cases reported no other ocular disorders. Tearing, alone or associated with other symptoms, was the main presentation of CNLDO (86.7\%). Bilateral CNLDO was the most commonly observed abnormality, alone or associated with others. The median age at diagnosis was one year. Of the cases, $53.3 \%$ were treated medically, $26.7 \%$ by surgical correction, and $13.3 \%$ required both.

\section{Conclusion}

Received 01/04/2020

Review began 01/04/2020 Review ended 01/12/2020 Published 01/15/2020

\section{() Copyright 2020}

Abdu et al. This is an open access article distributed under the terms of the Creative Commons Attribution License CC-BY 3.0., which permits unrestricted use, distribution, and reproduction in any medium, provided the original author and source are credited.
Bilateral CNLDO is the most observed disease pattern among children with Down syndrome. In our study, tearing was the most common clinical presentation and most cases were treated medically. Down syndrome patients should be carefully examined for nasolacrimal duct obstructions and treated medically.

\author{
Categories: Genetics, Ophthalmology, Pediatrics \\ Keywords: down syndrome, nasolacrimal duct, ophthalmology, genetic, pediatric
}

\section{Introduction}

Congenital nasolacrimal duct obstruction (CNLDO) is one of the most common congenital abnormalities encountered by pediatric ophthalmologists, occurring in $20-30 \%$ of all neonates (range: 6-84\%) [1-4]. It results from an obstruction at the valve of the Hasner membrane, and despite its high global rates of incidence, it clinically becomes symptomatic in only $2-6 \%$ of all affected infants [3,5]. Furthermore, the majority of the cases (up to 90\%) resolve within the first year of birth [6-7].

Several risk factors are associated with CNLDO, such as maternal infections during pregnancy, medication use, radiation exposure, some occupational hazards, and genetic predisposition [8].

Several studies have confirmed that amblyopia, also known as lazy eye, is one of the main complications caused by CNLDO, developing in approximately $22 \%$ of the children diagnosed with CNLDO [6,9-11]. Presenting features of CNLDO include constant epiphora and intermittent discharge involving one or both eyes $[3,12]$. In the majority of cases, it is considered a benign disease as far as visual development is concerned [3]. Normal development of the visual system early in life requires the presence of a sharply focused retinal image. The effect of persistent tearing on visual development in children is debatable and 


\section{Cureus}

inconclusive. Hypothetically, continuous watering due to CNLDO can lead to vision cloudiness and amblyopia during visual development [3].

Many syndromes are known to be associated with congenital lacrimal anomalies. The most common are Down syndrome and ectrodactyly ectodermal dysplasia-cleft (EEC) syndrome [13-16]. The prevalence of nasolacrimal anomalies in Down syndrome has been reported to be 22\% [13-14]. The prevalence of CNLDO in Saudi Arabia is estimated to be 2.6\% [17]. The literature concerning Saudi Arabia does not yet report on the prevalence of CNLDO in Down syndrome patients or the outcomes of different treatment options. Our study aims to describe the prevalence and clinical presentation of CNLDO among children diagnosed with Down syndrome and the treatment outcomes in a tertiary care centre in Saudi Arabia.

\section{Materials And Methods}

This was a retrospective review including all children diagnosed with Down syndrome at King Abdulaziz University Hospital (KAUH), Jeddah, Saudi Arabia between 2010 and 2015. Ethical approval was obtained from the technical and ethical committee at KAUH, as well as other administrative approvals from KAUH administration.

The records of pediatric patients diagnosed with Down syndrome per national guidelines within the above years were reviewed. We used a standardized data collection sheet designed from literature findings to collect the following patient information: (A) Demographic data (age, gender, and nationality), (B) Clinical profile (past medical history of other ocular disorders and chronic systemic conditions), (C) CNLDO presentation (age at presentation, symptoms and signs, disease pattern), and (D) CNLDO management and prognosis (prescribed medical treatments, type of surgical correction, and final treatment outcome).

Patients' personal information was kept confidential, and obtained data were coded and sorted for analysis. Descriptive statistical analysis was conducted using the Statistical Package for Social Sciences (SPSS) for Windows Version 22 (IBM Corp., Armonk, NY). Categorical data were represented in counts and frequencies, whereas continuous data were described in ranges and medians.

\section{Results}

The total sample size was 175 patients; 15 patients were diagnosed with CNLDO with prevalence of $8.57 \%$. Eight (53.3\%) males and seven (46.7\%) females, with a median age of eight years, were included in this review. Ten (66.7\%) of these patients were Saudi children (Table 1).

\begin{tabular}{|c|c|c|}
\hline Variable & $\mathbf{N}$ & $\%$ \\
\hline \multicolumn{3}{|l|}{ Gender } \\
\hline Male & 7 & 46.7 \\
\hline Female & 8 & 53.3 \\
\hline \multicolumn{3}{|l|}{ Nationality } \\
\hline Saudi & 10 & 66.7 \\
\hline Non-Saudi & 5 & 33.3 \\
\hline Variable & Median & Quartile (25-75) \\
\hline Age & 8 & (6-9) \\
\hline
\end{tabular}

TABLE 1: Demographic data

Regarding ocular disorders, three (20.0\%) cases were diagnosed with refractive error, two had nystagmus (13.3\%), and two cases had blepharitis (13.3\%). Myopia, strabismus, conjunctivitis, and cataract were observed in four different patients, and the remaining four cases reported no other ocular disorders. In terms of systemic diseases, congenital heart diseases were reported in four (18.2\%) cases, thyroid disorders were also reported in four (18.2\%) cases, atrial septal defects were reported in three (13.6\%) cases, and kidney diseases and neurological diseases were each reported in two (9.1\%) cases, whereas the remaining four (18.2\%) cases had no known systemic diseases (Table 2). Tearing, alone or associated with other symptoms, was the main presentation of CNLDO in 13 (86.7\%) cases. Bilateral CNLDO was the most commonly observed abnormality, alone or associated with others (Table 2). The median age at diagnosis was one year. 


\section{Cureus}

Variable

Ocular diseases

Refractive erro

Nystagmus

Blepharitis

Myopia

Strabismus

Conjunctivitis

Cataract

No ocular disease

Systematic diseases

None

Congenital heart disease

Atrial septal defect

Other heart diseases

Thyroid disorder

Kidney disease

Neurological diseases

Symptoms

Tearing; discharge in the eye

Discharge in the eye

Tearing

Tearing; discharge in the eye; Sleep with eyes open

Abnormalities

Bilateral

Bilateral; recurrent; tight nasolacrimal duct

Upward slanting of the palpebral fissure - epicanthal folds

\section{TABLE 2: Clinical characteristics}

Various treatment modalities were used for these patients. Medical treatment was used in eight (53.3\%) cases, followed by surgical correction in four $(26.7 \%)$ cases, and two $(13.3 \%)$ cases required both. The main medical treatment used in eight (53.3\%) cases was "Massage", while the main surgical method applied in three (20.0\%) cases was "Probing". Complete resolution was reported in nine (60.0\%) cases, and three cases reported a partial resolution.

\section{Discussion}

Down syndrome, a chromosomal anomaly caused by trisomy 21 , is one of the most common congenital anomalies. Several studies have reported its association with a number of ophthalmic features where the lacrimal drainage system is often influenced [13,17-18]. The incidence rate of nasolacrimal duct obstruction ranges between $5 \%$ and $30 \%[13,19]$. 
The nasolacrimal duct is formed by canalization of the caudal extremity of an epithelial cord derived from the ectoderm in the naso-optic fissure, which is often not completed at birth [1]. If there is a failure in the canalization of the nasolacrimal duct, particularly on the membrane of Hanser, CNLDO will occur [20]. There are three main clinical manifestations of CNLDO: persistent epiphora, increased tear lake, and recurrent mucopurulent discharge [20]. In the current study, tearing with or without discharge in the eye was the main symptom in all the cases.

Patients with Down syndrome that have CNLDO have anatomical abnormalities either as focal stenosis or diffuse stenosis, other than obstructions at its distal end [12]. The higher rate of CNLDO in Down syndrome could be explained in part to the unique facial morphology, and abnormal persistence of a membrane or bony obstruction along the distal portion of the nasolacrimal duct (NLD) [21].

There are two major treatment approaches for CNLDO, medically and surgically. In the current study, more than half of the patients were treated medically, mainly by massage. About a fourth of the patients were treated surgically, mainly by probing.

In a Brazilian study, most of the ophthalmologists (97.2\%) stated they used massage as the primary treatment approach until the age of one year [22]. Similar results were reported in a UK study, where 84.0\% of the ophthalmologists used massage as the primary approach until the age of one year [23]. The "wait-andsee" model associated with conservative therapies was confirmed in many studies to be a better treatment option in infants less than one year old [22-25].

As a patient ages, the rate of spontaneous resolution of CNLDO reduces, and surgical intervention, such as probing, must be performed. Probing can be performed under general anesthesia or sedation. In the Brazilian and UK studies, the procedure was performed under anesthesia in patients between the ages of 1215 months [22-23]. Probing is considered the first surgical option because of its ease of implementation [22].

The optimal timing for probing remains debatable. Several studies have recommended early probing, and the reason is that prolonged inflammation raises fibrosis in the obstructed sites. Moreover, Arora et al. concluded that probing with irrigation is considered primary management for congenital NLDO in children less than three years old. Based on their data and the results of many other studies, the failing of probing with irrigation as primary treatment is likely with children beyond age three along with other clinical factors [26-27]. On the other hand, other studies have reported probing to be an applicable surgical option for children between two and three years of age who present with primary CNLDO [28-30].

Our study limitations included retrospective design and varying follow-up duration.

\section{Conclusions}

The prevalence of CNLDO in Down syndrome patients was $8.57 \%$. Bilateral CNLDO is the most observed disease pattern among children with Down syndrome, with tearing as the most common clinical presentation. Patients are mostly treated medically. Therefore, we recommend that Down syndrome patients should be carefully examined for nasolacrimal duct obstructions.

\section{Additional Information \\ Disclosures}

Human subjects: Consent was obtained by all participants in this study. King Abdulaziz University (Unit of biomedical ethics and research committee) issued approval No 391-17. This research had been approved by the Research Ethics Committee on August 08, 2017. Based on the investigator request titled research/study proposal has been Re-examined and Committee grant the final ethical approval with following enclosures: Data collection sheet. - Conclusion abstract and the manuscript. Animal subjects: All authors have confirmed that this study did not involve animal subjects or tissue. Conflicts of interest: In compliance with the ICMJE uniform disclosure form, all authors declare the following: Payment/services info: All authors have declared that no financial support was received from any organization for the submitted work. Financial relationships: All authors have declared that they have no financial relationships at present or within the previous three years with any organizations that might have an interest in the submitted work. Other relationships: All authors have declared that there are no other relationships or activities that could appear to have influenced the submitted work.

\section{References}

1. Britto FC, Rosier VV, Luz TV, Verde RC, Lima CM, Lessa MM: Nasolacrimal duct mucocele: case report and literature review. Int Arch Otorhinolaryngol. 2015, 19:96-98. 10.1055/s-0034-1366978

2. Gujar SK, Gandhi D: Congenital malformations of the orbit. Neuroimaging Clin N Am. 2011, 21:585-602. 10.1016/j.nic.2011.05.004

3. Ramkumar VA, Agarkar S, Mukherjee B: Nasolacrimal duct obstruction: does it really increase the risk of amblyopia in children?. Indian J Ophthalmol. 2016, 64:496-499. 10.4103/0301-4738.190101

4. Leonard DS, O'Keefe M, Rowley H, Hughes JP: Neonatal respiratory distress secondary to bilateral intranasal 
dacryocystocoeles. Int J Pediatr Otorhinolaryngol. 2008, 72:1873-1877. 10.1016/j.ijporl.2008.09.011

5. Lorena SH, Silva JA, Scarpi MJ: Congenital nasolacrimal duct obstruction in premature children . J Pediatr Ophthalmol Strabismus. 2013, 50:239-244. 10.3928/01913913-20130423-01

6. Bagheri A, Safapoor S, Yazdani S, Yaseri M: Refractive state in children with unilateral congenital nasolacrimal duct obstruction. J Ophthalmic Vis Res. 2012, 7:310-315.

7. Kim JW, Lee H, Chang M, Park M, Lee TS, Baek S: Amblyopia risk factors in infants with congenital nasolacrimal duct obstruction. J Craniofac Surg. 2013, 24:1123-1125. 10.1097/SCS.0b013e3182902b3d

8. Aldahash FD, Al-Mubarak MF, Alenizi SH, Al-Faky YH: Risk factors for developing congenital nasolacrimal duct obstruction. Saudi J Ophthalmol. 2014, 28:58-60. 10.1016/j.sjopt.2013.09.007

9. Matta NS, Silbert DI: High prevalence of amblyopia risk factors in preverbal children with nasolacrimal duct obstruction. J AAPOS. 2011, 15:350-352. 10.1016/j.jaapos.2011.05.007

10. Ozgur OR, Sayman IB, Oral Y, Akmaz B: Prevalence of amblyopia in children undergoing nasolacrimal duct irrigation and probing. Indian J Ophthalmol. 2013, 61:698-700. 10.4103/0301-4738.124737

11. Silbert D, Matt NS, Quintanal A, Singman E: Incidence of amblyopia risk factors in children with nasolacrimal duct obstruction. J AAPOS. 2013, 17:618. 10.1016/j.jaapos.2013.06.019

12. Khan SH, Haq SM, ul Haq MI, Aziz SA: Frequency of congenital nasolacrimal duct obstruction . Pak J Med Res. 2012, 51:15-18.

13. Baran F, Kelly JP, Finn LS, Manning S, Herlihy E, Weiss AH: Evaluation and treatment of failed nasolacrimal duct probing in Down syndrome. J AAPOS. 2014, 18:226-231. 10.1016/j.jaapos.2013.12.018

14. Lee S, Kim N, Khwarg SI, Choung HK, Lee MJ: Congenital lacrimal fistula associated with Down syndrome . Graefes Arch Clin Exp Ophthalmol. 2012, 250:1515-1519. 10.1007/s00417-012-2081-X

15. Eter N, Zerres K, Propping P, Roggenkamper P, Spitznas M: Severe persistent nasolacrimal duct obstruction: a typical finding in ADULT syndrome. Br J Ophthalmol. 2006, 90:1206-1207. 10.1136/bjo.2006.093088

16. Ali MJ, Kamal S, Gupta A, Ali MH, Naik MN: Simple vs complex congenital nasolacrimal duct obstructions: etiology, management and outcomes. Int Forum Allergy Rhinol. 2015, 5:174-177. 10.1002/alr.21435

17. Darraj A, Barakat W, Kenani M, et al.: Common eye diseases in children in Saudi Arabia (Jazan) . Ophthalmol Eye Dis. 2016, 8:33-39. 10.4137/OED.S39055

18. Stein R: Smith's recognizable patterns of human malformation. Arch Dis Child. 2007, 92:562.

19. Coats DK, McCreery KM, Plager DA, Bohra L, Kim DS, Paysse EA: Nasolacrimal outflow drainage anomalies in Down's syndrome. Ophthalmology. 2003, 110:1437-1441. 10.1016/S0161-6420(03)00410-X

20. Kim JH, Hwang JM, Kim HJ, Yu YS: Characteristic ocular findings in Asian children with Down syndrome . Eye. 2002, 16:710-714. 10.1038/sj.eye.6700208

21. Lin AE, Chang YC, Lin MY, Tam KW, Shen YD: Comparison of treatment for congenital nasolacrimal duct obstruction: a systematic review and meta-analysis. Can J Ophthalmol. 2016, 51:34-40. 10.1016/j.jcjo.2015.10.002

22. Weiss AH, Baran F, Kelly J: Congenital nasolacrimal duct obstruction: delineation of anatomic abnormalities with 3-dimensional reconstruction. Arch Ophthalmol. 2012, 130:842-848. 10.1001/archophthalmol.2012.36

23. Schellini SA, Ariki CT, Sousa RL, Weil D, Padovani CR: Management of congenital nasolacrimal duct obstruction-Latin American study. Ophthalmic Plast Reconstr Surg. 2013, 29:389-392. 10.1097/IOP.0b013e31829bb162

24. Puvanachandra N, Trikha S, MacEwen CJ, Morris RJ, Hodgkins PR: A national survey of the management of congenital nasolacrimal duct obstruction in the United Kingdom. J Pediatr Ophthalmol Strabismus. 2010, 47:76-80. 10.3928/01913913-20100308-04

25. Takahashi Y, Kakizaki H, Chan WO, Selva D: Management of congenital nasolacrimal duct obstruction . Acta Ophthalmol. 2010, 88:506-513. 10.1111/j.1755-3768.2009.01592.x

26. Kapadia MK, Freitag SK, Woog JJ: Evaluation and management of congenital nasolacrimal duct obstruction . Otolaryngol Clin North Am. 2006, 39:959-977. 10.1016/j.otc.2006.08.004

27. Arora S, Koushan K, Harvey JT: Success rates of primary probing for congenital nasolacrimal obstruction in children. J AAPOS. 2012, 16:173-176. 10.1016/j.jaapos.2011.12.151

28. Limbu B, Akin M, Saiju R: Age-based comparison of successful probing in Nepalese children with nasolacrimal duct obstruction. Orbit. 2010, 29:16-20. 10.3109/01676830903207844

29. Kashkouli MB, Kassaee A, Tabatabaee Z: Initial nasolacrimal duct probing in children under age 5: cure rate and factors affecting success. J AAPOS. 2002, 6:360-363. 10.1067/mpa.2002.129041

30. Repka MX, Chandler DL, Beck RW, et al.: Primary treatment of nasolacrimal duct obstruction with probing in children younger than 4 years. Ophthalmology. 2008, 115:577-584. 10.1016/j.ophtha.2007.07.030 